\title{
Spectral Analysis and High-Performance Liquid Chromatography of the cis-trans Geometrical Isomers of 5,6-Epoxyretinal ${ }^{1}$
}

\author{
Masayoshi ITo, Akiko KodAmA, Takako YAMANE, \\ and Kiyoshi TSUKIDA ${ }^{2}$ \\ Kobe Women's College of Pharmacy, Motoyamakita-machi, \\ Higashinada-ku, Kobe 658, Japan
}

(Received September 16, 1982)

\begin{abstract}
Summary Spectral characterization of 5,6-epoxyretinal isomers (II) prepared by a regioselective epoxidation of the parent retinal isomers have been described. High-performance liquid chromatographic separation of epoxyretinals and a photoisomerization behavior of all-trans-5,6epoxyretinal (IIa) have been investigated.

Key Words 5,6-epoxyretinal, regioselective epoxidation, high-performance liquid chromatography, photoisomerization, spectral analysis, retinal
\end{abstract}

Bovine rhodopsin has been shown to contain 11-cis-retinal (Ic) bound via a Schiff-base linkage $(1,2)$, to the $\varepsilon$-amino group of a specific lysyl residue (3) of the apoprotein, opsin. However, the interaction of each part of 11-cis-retinal (Ic) with opsin in the rhodopsin molecule and the chromophoric structures of the unstable intermediate during the photobleaching process of rhodopsin have not been clarified chemically in detail. On the other hand, 5,6-epoxyretinoic acid has recently been noted with regard to the metabolism of retinol (vitamin A alcohol) and retinoic acid (vitamin A acid) $(4,5)$. In a previous communication (6), we reported on 5,6epoxyrhodopsin as a part of the studies to elucidate the protein-chromophore interaction in rhodopsin. In this paper, we describe the spectral characterization of 5,6-epoxyretinal isomers (IIa-IId), their separation by high-performance liquid chromatography (HPLC), and the photoisomerization behavior of all-trans-5,6epoxyretinal (IIa).

\section{MATERIALS AND METHODS}

Ultraviolet (UV) spectra were recorded on a Shimadzu UV 200S instrument.

${ }^{1}$ Retinoids and Related Compounds Part 5. Part 4 in the series: Chem. Pharm. Bull., 30, 4205-4207 (1982).

2 伊藤允好, 小玉晶子, 山根孝子, 月田 潔 
${ }^{1} \mathrm{H}$-Nuclear magnetic resonance $\left({ }^{1} \mathrm{H}-\mathrm{NMR}\right)$ spectra at $90 \mathrm{MHz}$ were determined on a NV-21 (Nippon Electric-Varian Co.) spectrometer using $\mathrm{CDCl}_{3}$ solutions. Mass spectra (MS) were determined on a JMS-01SG mass spectrometer; high-resolution measurements were made relative to perfluorokerosene as a reference. Preparative thin layer chromatography (TLC) was carried out silica gel plates (Merck silica gel $60 \mathrm{~F}_{254}$ precoated plates, 0.25 or $0.5 \mathrm{~mm}$ thickness).

General procedure of epoxidation. To a stirred solution of a retinal isomer in dry $\mathrm{CH}_{2} \mathrm{Cl}_{2}$ or dry $\mathrm{Et}_{2} \mathrm{O}, m$-chloroperbenzoic acid (equimolar amount to the retinal isomer) under a stream of nitrogen was added. The mixture was stirred in the dark at room temperature for $c a .2 \mathrm{hr}$ (reaction was followed by TLC) and poured into a saturated $\mathrm{NaHCO}_{3}$ solution. The organic layer was separated and the aqueous layer was extracted with ether several times. Combined organic layers were washed with brine and dried $\left(\mathrm{Na}_{2} \mathrm{SO}_{4}\right)$. Removal of the solvent by evaporation gave an organic oil which was purified by preparative TLC (eluent: $20 \%$ ether in $n$-hexane) to afford a 5,6-epoxyretinal isomer. All-trans-5,6-epoxyretinal (IIa, $415.6 \mathrm{mg}$ ) was obtained from all-trans-retinal (Ia, $302.5 \mathrm{mg}$ ) recovering the starting retinal (Ia, $72.5 \mathrm{mg}$ ). Yields and high resolution measurements of molecular weight of epoxyretinal isomers by MS were as follows:

$\begin{array}{lccc} & \text { yield } & \text { molecular weight }\left(\mathrm{C}_{20} \mathrm{H}_{28} \mathrm{O}_{2}\right) \\ & & \text { Calcd. } & \text { Found } \\ \text { all-trans-isomer (IIa) } & 69 \% & 300.209 & 300.209 \\ \text { 13-cis-isomer (IIb) } & 42 \% & 300.209 & 300.206 \\ \text { 11-cis-isomer (IIc) } & 40 \% & 300.209 & 300.208 \\ \text { 9-cis-isomer (IId) } & 47 \% & 300.209 & 300.210\end{array}$

Chromatography. All analytical works were performed with a ShimadzuDuPont 840 or 830 liquid chromatograph equipped with a UV detector. Operating conditions for HPLC were as follows: column, $\mu$-Porasil $(30 \times 0.4 \mathrm{~cm})$; pressure, $25 \mathrm{~kg} / \mathrm{cm}^{2}$; temperature, ambient; detection, UV at 254 or $360 \mathrm{~nm}$; mobile phase, $18 \%$ diethyl ether in $n$-hexane.

Photoisomerization procedure. Irradiation was carried out as follows: ca. $0.1 \%$ solution of all-trans-5,6-epoxyretinal (IIa) in each solvent was stirred in a flask and exposed to light from a $43-\mathrm{cm}$ long fluorescent lamp $(30 \mathrm{~W})$ at a distance of $15 \mathrm{~cm}$.

\section{RESULTS AND DISCUSSION}

All-trans-5,6-epoxyretinal (IIa) was reported (7) to be available by epoxidation of all-trans-retinyl acetate with monoperphthalic acid followed by saponification and $\mathrm{MnO}_{2}$-oxidation. It was found by our pursuit of this experiment that this method was not appropriate for obtaining the cis-5,6-epoxyretinal isomers since it gave a low yield of epoxidation and a high degree of isomerization during the procedure. We tried a direct epoxidation of all-trans-retinal (Ia) by $m$ chloroperbenzoic acid in the dark under nitrogen in dry $\mathrm{CH}_{2} \mathrm{Cl}_{2}$ to give all-trans- 
5,6-epoxyretinal (IIa) in $69 \%$ yield along with $17 \%$ of starting retinal (Ia). Regioselective epoxidation at 5,6-double bond was observed in the other cis-retinal isomers in $c a .40-50 \%$ yield retaining the cis-configuration of the parent retinals. The starting mono-cis-retinal isomers [13-cis-(Ib), 11-cis-(Ic), and 9-cis-(Id)] were obtained in a stereochemically pure form from the irradiated mixture of acetonitrile solution of all-trans-retinal (Ia) using the preparative HPLC technique developed in our laboratory $(8)$. The structure of epoxyretinals was confirmed on the basis of the $\mathrm{UV}$ and ${ }^{1} \mathrm{H}-\mathrm{NMR}$ data. Their characteristic spectral data are compiled in Tables 1 and 2 . The chemical shift of 5-methyl signals $(\delta 0.92-0.97)$ strongly suggests that the 5,6-double bond of retinals is regioselectively epoxidized. This is also supported by the fact that UV absorption maxima of epoxidized retinal isomers are $c a .15 \mathrm{~nm}$ shorter in wavelength than the respective parent retinals. The 13-cis-geometry is clearly evidenced by a strong downfield shift of the signal of $12-\mathrm{H}$ and the upfield shift of the 13-methyl signal. A $\Delta^{9}$-cis-configuration is recognizable from a downfield shift of the 8-H signal. The geometry of 7,8- and 11,12-double bonds can be readily determined from the magnitude of the vinyl coupling constants. It is of interest that the signals of $7-\mathrm{H}$ and $8-\mathrm{H}$ are more separated than those (9) of the parent retinals with the effect of 5,6-epoxide ring.

HPLC-chromatogram of a mixture of pure four 5,6-epoxyretinal isomers is shown in Fig. 2. Mobile phase for epoxyretinals is more polar than those for retinal $(10,11)$, 3-dehydroretinal (12), and retro- $\gamma$-retinal (13). Each cis-isomer in these series has been eluted in the order of 13-cis $>11$-cis $>9$-cis $>7$-cis. The

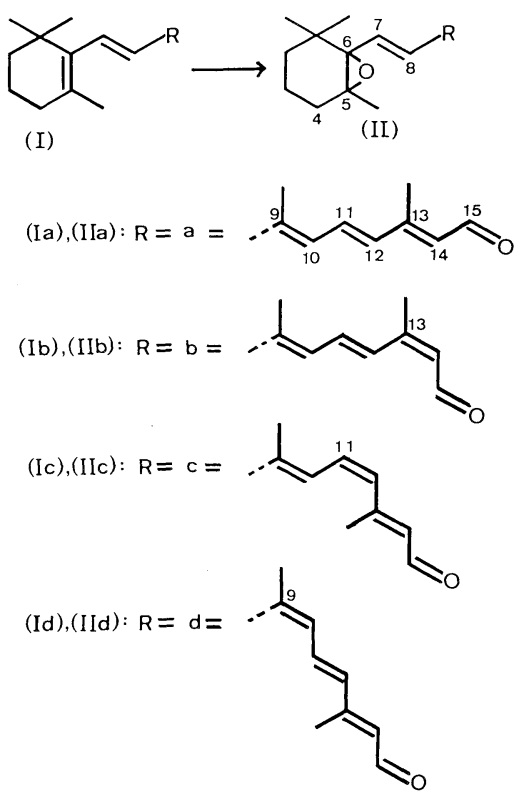

Fig. 1. Structures of retinal and 5,6-epoxyretinal isomers.

Vol. 29, No. 2, 1983 
Table 1. UV data for 5,6-epoxyretinal isomers.

\begin{tabular}{lcccc}
\hline \multicolumn{1}{c}{ Isomer } & $\lambda_{\max }^{\text {EtoH }} \mathrm{nm}$ & $\varepsilon$ & $\lambda_{\text {max }}^{\text {Hex. }} \mathrm{nm}$ & $\varepsilon$ \\
\hline all-trans (IIa) & 365 & 53,500 & 351 & 28,500 \\
13-cis (IIb) & 359 & 40,400 & 347 & 31,400 \\
11-cis (IIc) & 362 & 37,200 & 351 & 19,400 \\
& 252 & 18,600 & 250 & 8,000 \\
9-cis (IId) & 358 & 44,300 & 347 & 27,400 \\
\hline
\end{tabular}

Table 2. ${ }^{1} \mathrm{H}-\mathrm{NMR}$ data ${ }^{\mathrm{a}}$ of isomers of 5,6-epoxyretinal.

\begin{tabular}{lcccc}
\hline & $\begin{array}{c}\text { all-trans } \\
\text { (IIa) }\end{array}$ & $\begin{array}{c}13 \text {-cis } \\
\text { (IIb) }\end{array}$ & $\begin{array}{c}11 \text {-cis } \\
\text { (IIc) }\end{array}$ & $\begin{array}{c}9 \text {-cis } \\
\text { (IId) }\end{array}$ \\
\hline $13-\mathrm{CH}_{3}$ & 2.31 & 2.14 & 2.34 & 2.32 \\
$9-\mathrm{CH}_{3}$ & 1.98 & 2.00 & 1.92 & 1.99 \\
$5-\mathrm{CH}_{3}$ & 0.92 & 0.94 & 0.92 & 0.97 \\
gemCH $_{3}$ & 1.09 & 1.11 & 1.08 & 1.12 \\
$15-\mathrm{H}$ & 1.13 & 1.14 & 1.12 & 1.17 \\
$14-\mathrm{H}$ & 10.13 & 10.24 & 10.10 & 10.14 \\
$12-\mathrm{H}$ & 6.00 & 5.89 & 6.00 & 5.98 \\
$11-\mathrm{H}$ & 6.38 & 7.35 & 6.05 & $6.33^{\mathrm{b}}$ \\
$10-\mathrm{H}$ & 7.13 & 7.02 & 6.68 & 7.27 \\
$8-\mathrm{H}$ & 6.11 & 6.29 & $?$ & 6.11 \\
$7-\mathrm{H}$ & 6.04 & 6.07 & 6.03 & 6.89 \\
$J_{14-15}$ & 6.38 & 6.40 & 6.34 & $8.10^{\mathrm{b}}$ \\
$J_{11-12}$ & 8 & 8 & 8 & 15 \\
$J_{10-11}$ & 15 & 15 & 9 & 12 \\
$J_{7-8}$ & 11 & 10 & 9 & 15 \\
\hline
\end{tabular}

${ }^{\mathrm{a}}$ Chemical shift in $\delta$, coupling constant in $\mathrm{Hz}$. Solvent: $\mathrm{CDCl}_{3} \cdot{ }^{\mathrm{b}}$ Assignments may be reversed.

order is proportional to the distance of the cis-double bond from the aldehyde group. Using this HPLC result, a photoisomerization behavior of all-trans-5,6epoxyretinal (IIa) was investigated to compare with those of other conjugated polyenals. Relative concentrations $(\%)$ of the isomers of 5,6-epoxyretinal obtained by photoisomerization are shown in Table 3. The data are results of determination after correction for different molar absorptivities of the isomers at $360 \mathrm{~nm}$, the wavelength of analysis. It is clear that the photoisomerization occurs mainly at the trisubstituted $\mathrm{C}=\mathrm{C}$ double bond adjacent to the carbonyl group of the conjugated tetraenal system. We had reported that the photoisomerization pattern was different in the three types of polyenals mentioned above. Particularly, in the pentaenal (retinal) and the hexaenal (3-dehydroretinal) series, the photoisomerization results 


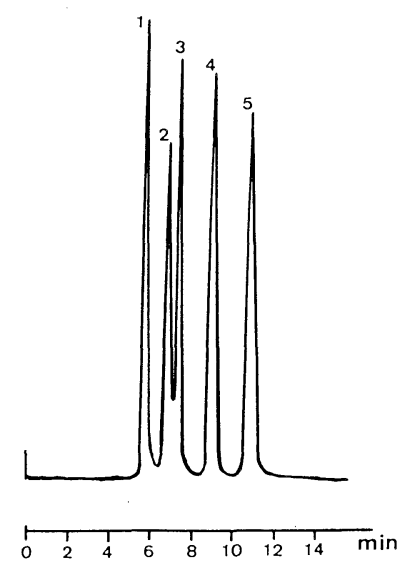

Fig. 2. High-performance liquid chromatogram of 5,6-epoxyretinal isomers. 1, oxylenol (internal standard); 2, 13-cis-isomer (IIb); 3, 11-cis-isomer (IIc); 4, all-transisomer (IIa); 5, 9-cis-isomer (IId). Shimadzu-DuPont $840, \mu$-Porasil $(30 \times 0.4 \mathrm{~cm})$, $18 \%$ ether in $n$-hexane, UV $254,25 \mathrm{~kg} / \mathrm{cm}^{2}$.

Table 3. Photoisomerization of all-trans-5,6-epoxyretinal in various solvents. ${ }^{\mathrm{a}}$

\begin{tabular}{lcccc}
\hline \multirow{2}{*}{ Solvent } & \multicolumn{5}{c}{$\begin{array}{c}\text { Isomer } \\
\text { Percentage composition }\end{array}$} \\
\cline { 2 - 5 } & $\begin{array}{c}\text { all-trans } \\
\text { (IIa) }\end{array}$ & $\begin{array}{c}13 \text {-cis } \\
\text { (IIb) }\end{array}$ & $\begin{array}{c}11 \text {-cis } \\
\text { (IIc) }\end{array}$ & $\begin{array}{c}\text { 9-cis } \\
\text { (IId) }\end{array}$ \\
\hline$n$-Hexane & 63.7 & 29.3 & 2.4 & 4.6 \\
Methanol & 38.5 & 43.1 & 15.9 & 2.5 \\
iso-Propanol & 37.1 & 50.3 & 10.4 & 2.2 \\
DMSO & 45.3 & 41.6 & 9.8 & 3.3 \\
Acetonitrile & 53.6 & 33.2 & 9.4 & 3.8 \\
THF & 61.4 & 31.9 & 2.7 & 4.0 \\
Acetone & 56.5 & 34.6 & 4.5 & 4.4 \\
DMF & 49.3 & 40.1 & 7.0 & 3.6 \\
\hline
\end{tabular}

${ }^{\mathrm{a}}$ Irradiation time, $3 \mathrm{~h}$.

were strongly affected by the solvents used (i.e. in the aprotic polar solvent acetonitrile $(10,12)$, predominant $c i s$-isomerization at $\Delta^{11}$ (retinal) or $\Delta^{9}$ (3-dehydroretinal) occurred.). However, in the trienal (retro- $\gamma$-retinal), the results were not as affected by the solvent. In comparison of the present photoisomerization behavior with the previous results, it seems that despite the kind of solvent, the position of predominant photoisomerization in the conjugated trienal and tetraenal is the $\mathrm{C}=\mathrm{C}$ double bond adjacent to the aldehyde group. 
We gratefully thank Misses M. Murata, M. Kobayashi, J. Okuno, and A. Nozu for technical assistance.

\section{REFERENCES}

1) Bownds, D. (1967): Site of attachment of retinal in rhodopsin. Nature, 216, 1178-1181.

2) Akhtar, M., Blosse, P. T., and Dewhurst, P. B. (1968): Studies on vision. Biochem. J., 110, 693-702.

3) Mullen, E., and Akhtar, M. (1981): Topographic and active-site studies on bovine rhodopsin. FEBS Lett., 132, 261-264.

4) McCormick, A. M., Napoli, J. L., Schnoes, H. K., and DeLuca, H. F. (1978): Isolation and identification of 5,6-epoxyretinoic acid: a biologically active metabolite of retinoic acid. Biochemistry, 17, 4085-4090.

5) Zile, M. H., Inhorn, R. C., and DeLuca, H. F. (1980): The biological activity of 5,6epoxyretinoic acid. J. Nutr., 110, 2225-2230.

6) Ito, M., Kodama, A., Murata, M., Kobayashi, M., Tsukida, K., Shichida, Y., and Yoshizawa, T. (1979): 5,6-Epoxyretinals and visual pigment analogs. J. Nutr. Sci. Vitaminol., 25, 343-345.

7) Jungalwala, F. B., and Cama, H. R. (1965): Preparation and properties of 5,6monoepoxyvitamin A acetate, 5,6-monoepoxyvitamin A alcohol, 5,6-monoepoxyvitamin A aldehyde and their corresponding 5,8-monoepoxy (furanoid) compounds. Biochem. J., 95, 17-26.

8) Tsukida, K., Kodama, A., and Ito, M. (1978): A rapid and convenient acquisition of the pure 11-cis retinal specimen by preparative high-performance liquid chromatography. J. Nutr. Sci. Vitaminol., 24, 593-596.

9) Ramamurthy, V., and Liu, R. S. H. (1975): 7-Cis isomers of retinal via 7-cis- and 7,9dicis- $\beta$ - $\mathrm{C}_{18}$-tetraene ketones. Tetrahedron, 31, 201-206.

10) Tsukida, K., Kodama, A., and Ito, M. (1977): Simultaneous determination of cis-trans isomeric retinals by high-performance liquid chromatography. J. Chromatogr., 134, 331-336.

11) Denny, M., and Liu, R. S. H. (1977): Sterically hindered isomers of retinal from direct irradiation of the all-trans isomer. Isolation of 7-cis-retinal. J. Am. Chem. Soc., 99, 4865-4867.

12) Tsukida, K., Masahara, R., and Ito, M. (1980): High-performance liquid chromatographic analysis of cis-trans stereoisomeric 3-dehydroretinals in the presence of retinal isomers. J. Chromatogr., 192, 395-401.

13) Ito, M., Kodama, A., and Tsukida, K. (1981): Retinoids and related compounds. II. High-performance liquid chromatographic analysis of the irradiation products of 9-cisretro-y-retinal. Chem. Pharm. Bull., 29, 3385-3387. 